\title{
TURISMO E IMPACTOS AMBIENTAIS NO BALNEÁRIO MUNICIPAL DE ROSANA - SP
}

\author{
Glenda Lislie Maciel Alves; Danielli Cristina Granado
}

Universidade Estadual Paulista - UNESP, curso de Turismo, Rosana, SP. E-mail: glenda lislie@hotmail.com

\section{RESUMO}

A preferência da população em usufruir de ambientes aquáticos para recreação é evidente no Brasil, que possui grande potencialidade hídrica e inúmeras opções de destinos relacionados ao tema. Mas a popularização do segmento tem provocado alterações crescentes nesses espaços. 0 objetivo deste trabalho foi analisar os impactos ambientais negativos no Balneário Municipal de Rosana (SP), relacionando-os ao uso para recreação e turismo. Foi realizado levantamento bibliográfico e trabalho de campo para observações in loco e aplicação de uma avaliação simplificada de impactos ambientais. Os resultados demonstraram alterações antrópicas nas duas estações amostradas, as quais foram classificadas como ambientes com moderada presença de impactos ambientais. Conclui-se que o turismo, em grande parte das vezes, carece de planejamento adequado e não contempla ações voltadas para o monitoramento e a conservação dos ecossistemas aquáticos, que busquem assegurar a qualidade ambiental e à saúde dos banhistas, garantindo a continuidade do atrativo em longo prazo.

Palavras chave: turismo; impactos ambientais; ambientes aquáticos, balneários.

\section{TOURISM AND ENVIRONMENTAL IMPACTS ON WATERING PLACE OF ROSANA - SP}

\begin{abstract}
The preference of the population enjoy aquatic environments for recreation is evident in Brazil, which has large hydric potential and numerous choices of destinations related to the topic. But the popularity of the segment caused changes in these spaces. The objective of this study was to analyze the negative environmental impacts in Balneario Municipal de Rosana (SP), relating them to use for recreation and tourism. It was performed literature review and fieldwork to observations and implementing a simplified environmental impact assessment. The results showed anthropogenic changes in two stations sampled the Municipal Beach, which were classified as moderate environments with the presence of environmental impacts. The conclusion is that tourism, in large part, lacks proper planning and does not contemplate actions for the monitoring and conservation of aquatic ecosystems, striving to ensure the environmental quality and the health of bathers, ensuring continuity of attractive.
\end{abstract}

Keywords: tourism; environmental impacts; aquatic environments. 


\section{INTRODUÇÃO}

A preferência da população em usufruir de ambientes aquáticos para fins de lazer e recreação é bastante evidente no Brasil, como mostram algumas pesquisas como as realizadas por Queiroz (2000), Ferretti (2002) e ANA (2005). O país possui uma grande potencialidade hídrica e oferece inúmeras opções de destinos que envolvem a prática do lazer e recreação associada aos recursos hídricos.

No entanto, com a popularização do segmento, o chamado turismo massificado de Sol e Praia tem provocado alterações crescentes nesses espaços. A retirada da vegetação para implantação da infraestrutura e equipamentos turísticos, o pisoteamento excessivo e a destruição de hábitats são alguns exemplos de impactos negativos, que levam a degradação da paisagem e comprometem sua qualidade ambiental.

De acordo com Mendonça (2001), o turismo tradicional ou de massa segue o padrão capitalista da sociedade contemporânea, com caráter frequentemente predatório, que degrada os locais dos quais se apropria. Segundo Cruz (2003), o turismo de massa é definido por como:

Uma forma de organização do turismo que envolve o agenciamento da atividade bem como a interligação entre agenciamento, transporte e hospedagem, de modo a proporcionar o barateamento dos custos da viagem e permitir, consequentemente, que um grande número de pessoas viaje.

No Brasil, o turismo de massa ainda é predominante, sobretudo nos destinos de sol e praia, como na região Nordeste, cujas características marcantes são as bandeiras internacionais de empreendimentos turísticos, o grande número de turistas estrangeiros e a baixa absorção da mão de obra local.

Entretanto, outros ambientes aquáticos passaram a se destacar no cenário turístico nacional, entre eles, rios e lagos de hidrelétricas (ANA, 2005). Embora apresentem um fluxo mais regional de visitantes, a procura por tais locais se encontra em ascensão. Deste modo, muitos locais já estão sofrendo degradação, já que na maioria dos casos, a atividade turística carece de planejamento adequado e não contempla ações e programas voltados para o monitoramento e a conservação dos ecossistemas aquáticos que busquem assegurar a qualidade ambiental e à saúde dos banhistas, garantindo assim, a continuidade do atrativo, em longo prazo (GRANADO; ROMERO, 2014; GRANADO; RIBEIRO; LOPES, 2015).

Neste contexto, este trabalho tem como objetivo analisar os impactos ambientais negativos no Balneário Municipal de Rosana (SP), relacionando ao uso para recreação e turismo, por meio da aplicação de uma avaliação simplificada de impactos ambientais. 


\section{Caracterização da Área de Estudo}

Rosana é um município Paulista com população estimada em 19.691 habitantes (IBGE, 2014). Localiza-se no extremo oeste do Estado numa região conhecida como Pontal do Paranapanema. Seu território encontra-se delimitado ao sul pelo rio Paranapanema e a oeste pelo rio Paraná, onde está instalado o Balneário Municipal de Rosana.

O Balneário é o principal espaço de lazer e recreação da população local (DIAS; GRANADO, 2015), sendo considerado também como o mais importante atrativo turístico pelo Poder Público Municipal. Apresenta infraestrutura básica e equipamentos relacionados à recreação como rampa para barcos, parque infantil, quadra de areia, área de camping, lanchonetes e academia para terceira idade, além de uma base do Corpo de bombeiros (Figuras 1 e 2).

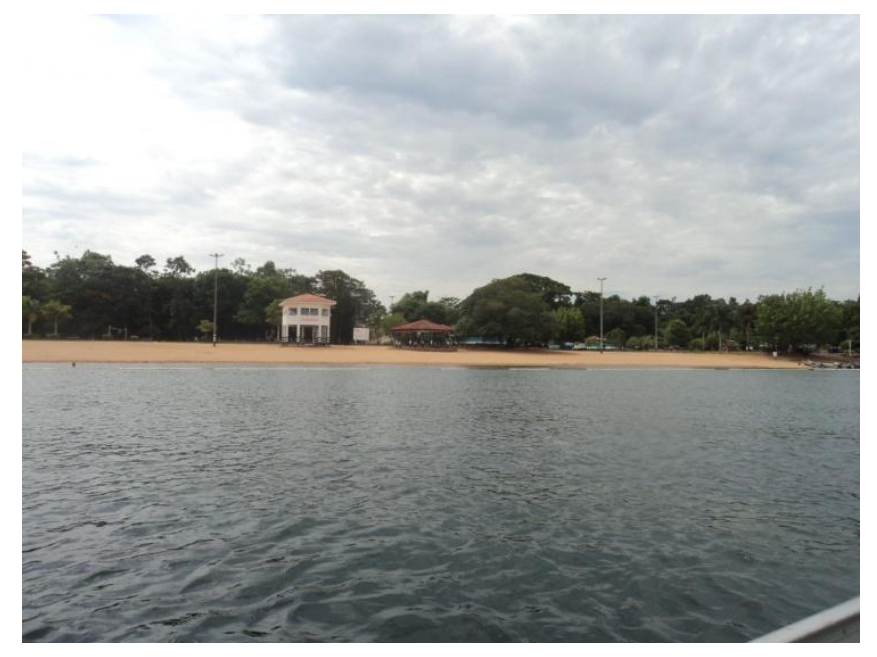

Figura 1. Balneário Municipal de Rosana (Foto: GRANADO, 2013).

Neste estudo foram amostradas duas estações que são os locais mais frequentados pelos visitantes do Balneário Municipal, sendo elas a Estação 1: área destinada para banho dos frequentadores, que é delimitada com boias de proteção para delimitar até onde os banhistas podem chegar, em função da profundidade, localizada em frente à base do Corpo de Bombeiros; e a Estação 2: área onde localiza-se um píer de rochas, destinado apenas para uso contemplativo e pesca (Figura 2). 


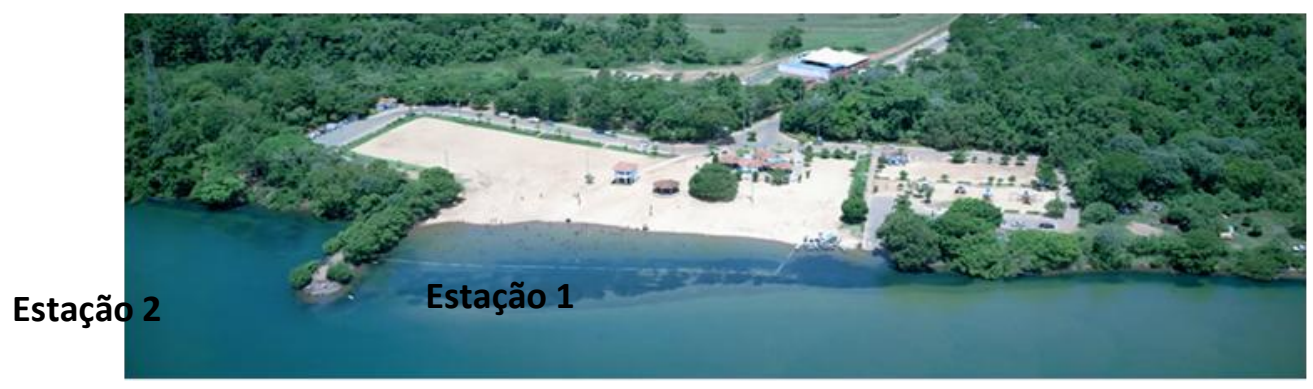

Figura 2. Foto aérea do Balneário Municipal de Rosana, demonstrando as estações amostradas (Fonte: ROSANA, 2012).

\section{MATERIAL E MÉTODOS}

Para alcançar os objetivos propostos foram realizados levantamento bibliográfico e trabalho de campo. O primeiro para compreender a apropriação e o uso dos ambientes aquáticos pelo turismo; e o segundo para permitir observações in loco e aplicação de um instrumento de avaliação simplificada de impactos ambientais.

Durante os trabalhos de campo, que aconteceram em dias alternados durante uma semana de junho e julho de 2015, foi aplicado o protocolo de avaliação simplificada de impactos ambientais proposto por Salles et al. (2008), abrangendo os seguintes indicadores ambientais: cobertura vegetal no entorno, existência de fauna no entorno, presença de resíduos sólidos, aspectos relacionados ao saneamento, presença de erosão, riscos associados à erosão, presença de sons e ruídos e danos à paisagem. Para cada indicador são atribuídos valores, cuja soma resultará na classificação do ambiente, quanto ao nível de impacto existente em: altamente impactados (abaixo de 6 pontos), nível de impacto elevado ou preocupante ( $7-12$ pontos), moderada presença de impactos negativos (13 - 18 pontos) e baixa presença de impactos (19 - 24 pontos).

Além da aplicação da avaliação ambiental no ambiente terrestre, ainda foram observados aspectos estéticos, visuais e olfativos associados à qualidade da água, como a presença de óleos e graxas e odor na água e no sedimento, em cada uma das estações amostradas. A turbidez da água foi mensurada por meio de um turbidímetro HANNA.

Em cada um dos meses amostrados foram realizadas quatro mensurações, tanto para a avaliação ambiental, quanto para a turbidez, totalizando oito amostragens. Os dados foram então transformados em médias mensais, sendo acompanhados de cálculos de desvio padrão e coeficiente de variação. 


\section{Análise dos Impactos Ambientais no Balneário Municipal de Rosana}

A avaliação simplificada de impactos ambientais demonstrou alterações antrópicas nas duas estações amostradas do Balneário Municipal. Durante o período de estudo, os locais foram classificados como ambientes com moderada presença de impactos ambientais, a partir da aplicação do protocolo de Salles et al. (2008), como mostra a Tabela 1, que apresenta os valores médios, o desvio padrão e o coeficiente de variação de cada mês. Evidencia-se que foram utilizados valores médios, devido aos baixos valores de desvio padrão e coeficiente de variação observados.

Tabela 1. Valores médios, desvio padrão e coeficiente de variação da avaliação ambiental aplicada em junho e julho de 2015.

\begin{tabular}{|l|c|c|c|c|}
\hline & \multicolumn{2}{|c|}{ Junho } & \multicolumn{2}{c|}{ Julho } \\
\hline & Estação 1 & Estação 2 & Estação 1 & Estação 2 \\
\hline Média & 15 & 14 & 14 & 14 \\
\hline Desvio Padrão & 2,1 & 1,3 & 0,6 & 1,7 \\
\hline $\begin{array}{l}\text { Coeficiente de } \\
\text { Variação }\end{array}$ & 13,5 & 9,2 & 4,3 & 12,0 \\
\hline
\end{tabular}

Os principais parâmetros que comprometeram a avaliação ambiental estiveram relacionados à presença de erosão nas margens, a cobertura vegetal e a presença de resíduos sólidos. A erosão esteve mais acentuada na estação 2 , onde foram observados sulcos profundos pela passagem da águas, enquanto que na estação 1 foram encontradas apenas ravinas, mas ambos locais necessitam de providências para conter as águas pluviais, devido aos prejuízos da erosão ao curso de água, ocasionado pelo assoreamento.

A cobertura vegetal apresentou-se mais comprometida na estação 1, onde foi observada ausência de qualquer forma de vegetação, enquanto que na estação 2 , predominou a vegetação arbustiva. Essa constatação deve-se ao fato de que a estação 1 é a área de praia, propriamente dita, a qual foi artificialmente transformada para atender os usos recreativos de contato primário, principalmente o banho.

A presença de resíduos sólidos no entorno foi observada em ambas as estações do Balneário Municipal, embora em quantidade moderada, essa constatação preocupa já que se trata de período de baixa temporada para a visitação. Deste modo, essa quantidade pode aumentar significativamente, a partir do aumento da visitação nos meses de alta temporada (dezembromarço). Outros impactos observados estiveram relacionados à existência de danos à paisagem, os 
quais foram encontrados principalmente na estação 2, com a presença de raízes expostas e inscrições em rochas.

Os níveis de turbidez da água variaram de a nos dias amostrados. Nesse parâmetro, os dois ambientes apresentaram resultados bem próximos entre 3,6 a 6,6 NTU. A Tabela 2 apresenta os valores médios, desvio padrão e coeficiente de variação de cada local. A estação 2 apresentou os melhores resultados, que pode ser explicado pela presença de vegetação arbustiva nessa área, que dificulta o processo de assoreamento do rio que tem relação com o nível de turbidez da água.

Tabela 2. Valores médios, desvio padrão e coeficiente de variação da análise de turbidez da água realizada em junho e julho de 2015.

\begin{tabular}{|l|c|c|c|c|}
\hline & \multicolumn{2}{|c|}{ Junho } & \multicolumn{2}{c|}{ Julho } \\
\hline & Estação 1 & Estação 2 & Estação 1 & Estação 2 \\
\hline Média & 3,9 & 3,9 & 4,9 & 4,5 \\
\hline Desvio Padrão & 0,2 & 0,3 & 1,1 & 0,5 \\
\hline $\begin{array}{l}\text { Coeficiente de Variação } \\
(\%)\end{array}$ & 5,2 & 7,5 & 23,2 & 10,8 \\
\hline
\end{tabular}

Os impactos ambientais observados estão relacionados ao fato de que balneários são espaços construídos com fins de lazer e recreação. Portanto precisam sofrer modificações para receber uma infraestrutura básica e turística, que atenda as necessidades do frequentador.

Segundo Nascimento (2005), a infraestrutura turística também representa um tipo de impacto na área natural. No entanto, a presença de estrutura mínima, como sanitários, locais para preparo de alimentos e coleta de lixo entre outros nos destinos turísticos, é importante tanto para o conforto dos visitantes quanto para gerar menos impactos ambientais no local, isso porque, sem a presença desses equipamentos o visitante irá utilizar qualquer outro lugar do ambiente natural para suprir suas necessidades. Assim, apesar da infraestrutura representar um tipo de impacto, ela ajuda a minimizar outros impactos potenciais mais graves.

Alguns municípios que possuem balneários em rios têm considerado o aproveitamento desses espaços para atividades de turismo como mais uma opção de geração de renda, como é o caso de Rosana, que participa inclusive de circuito turístico, chamado de "Oeste Rios", o qual tem como propósito promover o turismo na região do Pontal do Paranapanema.

Os balneários, além de propiciarem lazer de baixo custo à população local, podem atrair turistas para a localidade, contribuindo dessa forma, para que a economia, a infraestrutura e os recursos políticos do município possam se desenvolver para atender a demanda de visitantes (GRANADO; ROMERO, 2014). 
Para entender as alterações provocadas pelo turismo, é preciso levar em conta que essa atividade se apropria e modifica os espaços, podendo causar impactos positivos e negativos ao meio ambiente. São positivos quando trazem benefícios às localidades, como o desenvolvimento econômico, geração de empregos e valorização da cultura. E negativos quando prejudicam o destino, comprometendo seu poder de atração, como é o caso de praias poluídas pelo fluxo intenso de visitações. Também é preciso compreender a amplitude do impacto, que envolve além do meio natural, as esferas social e econômica. Diante disso, segundo Ferretti (2002), a análise dos impactos, positivos ou negativos que o turismo pode causar no ambiente, dependerá do planejamento do poder público.

Todavia, o que se observa na prática é que o turismo tem gerado diversos impactos negativos aos ambientes naturais, relacionados à recursos como vegetação, fauna, solo e recursos hídricos dos destinos turísticos, geralmente decorrentes da falta de um planejamento prévio da atividade. Os impactos negativos sobre os ambientes naturais podem levar ao esgotamento dos recursos, ocasionar desequilíbrios nos ecossistemas e comprometer o próprio desenvolvimento da atividade econômica.

Quando se pensa na implantação de qualquer atividade turística, o planejamento é fundamental para organizar e desenvolver o turismo de forma sustentável, de modo que seus impactos negativos sejam minimizados e seus impactos positivos maximizados. O planejamento turístico é capaz apontar quais potenciais podem ser explorados em benefícios dos turistas e que tragam desenvolvimento para a localidade, que na maioria das vezes, vê nesse setor uma possibilidade de aumentar sua receita. Também estabelecer no plano de desenvolvimento do turismo quais estratégias serão usadas para preparar a população receptora, criando uma cultura turística, pautada pelo sentimento de pertencimento local. Pois quando isso ocorre, a própria comunidade demonstra preocupação em conservar os recursos naturais locais.

Planejar e desenvolver espaços turísticos para atender a comunidade local e os turistas, não é fácil, mas deve constituir a meta dos poderes públicos, que se vêem muitas vezes diante de dois objetivos conflitantes: o primeiro de promover acesso ao uso recreacional ao maior número de pessoas possível, e o segundo de proteger e poupar descaracterizações dos locais de belezas naturais e de patrimônio cultural (RUSCHMANN, 2003).

\section{CONSIDERAÇÕES FINAIS}

Os balneários além de ofertar lazer para as populações locais, ainda apresentam potencial para atrair visitantes e a partir dessa movimentação de pessoas podem surgir atividades ligadas ao 
setor turístico, gerando emprego e renda para as populações, levando desenvolvimento às regiões onde se insere e assim passa a exercer um importante papel na economia de pequenas cidades.

Mas em geral, o que frequentemente se observa é que embora os ambientes aquáticos estejam entre os principais atrativos dos destinos turísticos, seus usos não estão integrados numa perspectiva de uso e conservação no escopo do planejamento urbano, turístico e ambiental das localidades.

Nas pequenas cidades, o problema se agrava, já que na maioria das vezes não há programas que tenham como objetivo melhorar e conservar esses espaços do ponto de visa de sua qualidade ambiental e da qualidade de vida dos frequentadores. Este é caso do Balneário Municipal de Rosana, que carece de um programa voltado à conservação e ao monitoramento de suas águas e dos espaços associados, que considere os usos múltiplos, principalmente a balneabilidade para fins de lazer e turismo, visto que os principais parâmetros que comprometeram a avaliação ambiental estiveram relacionados a presença de erosão nas margens, a cobertura vegetal e a presença de resíduos sólidos.

Conclui-se assim que a atividade turística, em grande parte das vezes, carece de planejamento adequado e não contempla ações e programas voltados para o monitoramento e a conservação dos ecossistemas aquáticos, que busquem assegurar a qualidade ambiental e à saúde dos banhistas, garantindo assim, a continuidade do atrativo, em longo prazo. Diante da exploração crescente dos ecossistemas aquáticos pelo turismo, estudos que demonstrem a qualidade ambiental são indispensáveis, de forma a contribuir para a gestão adequada dos recursos hídricos e a compatibilização dos usos múltiplos, assim como para minimizar os riscos a saúde dos usuários pelo contato com águas contaminadas.

Agradecimentos: As autoras agradecem à Fundação de Amparo à Pesquisa do Estado de São Paulo - FAPESP, pela bolsa de iniciação científica concedida (Processo 2014/27021-0) e pelos recursos disponibilizados por meio do Projeto Regular (Processo 2014/27211-4).

\section{REFERÊNCIAS}

Agência Nacional das Águas - ANA. (2005). Caderno de Recursos Hídricos: o turismo e o lazer e sua interface com 0 setor de recursos hídricos. Brasília. (http://www.ana.gov.br/ pnrh_novo/documentos/06\%20Turismo/VF\%20Turismo\%20Lazer.pdf. Acesso em: 20 de março de 2011. ARANHA, M. L. de A; MARTINS, M. H. P. Filosofando: Introdução à Filosofia. São Paulo, SP: Moderna, 2003.

CRUZ, R. C. A. Introdução à geografia do turismo. 2ed. São Paulo: Roca, 2003. 
FERRETTI, R. R. Turismo e meio ambiente. São Paulo: Roca, 2002. 170p.

GRANADO, D. C.; ROMERO, L. R. Lazer e turismo na represa de Jurumirim. In:

HENRY, R. Represa de Jurumirim: ecologia, modelagem e aspectos sociais. Ribeirão Preto, SP: Holos, 2014, p.367-376.

MENDONÇA, R. Turismo ou meio ambiente: uma falsa oposição. In: Impactos socioambientais do turismo, 2001. p. $19-25$.

NASCIMENTO, M. Turismo e recreação nas praias do baixo Rio Negro: uma avaliação retrospectiva de impactos ambientais. 2005. 114f. Tese (mestrado em Ciências Biológicas)Instituto Nacional de Pesquisas da Amazônia, Universidade Federal do Amazônas, Manaus. 2005. Disponível em: <http://www.globalgarbage.org/praia/downloads/dissertacao_mauro_do_nascimento.pdf>. Acesso em: 06 de maio de 2015.

RUSCHMANN, D. Turismo e planejamento sustentável. 10a Ed. Campinas- SP: Papirus, 2003. 199 p.

SALLES, M. H. D.; CONCEIÇÃO, F. T.; ANGELUCCI, V. A. et al. Avaliação simplificada de impactos $\begin{array}{lllll}\text { ambientais na bacia do alto Sorocaba } & \text { (SP).Disponível }\end{array}$ em:<http://ad.rosana.unesp.br/docview/directories/Arquivos/Cursos/Apoio\%20Did\%C3\%A1tico/ Danielli\%20Cristina\%20Granado\%20Romero/Est\%C3\%A1gio/Avalia\%C3\%A7\%C3\%A30\%20Simplific ada\%20de\%20Impactos\%20Ambientais.pdf>Acesso em: 05 de dez. de 2014. 